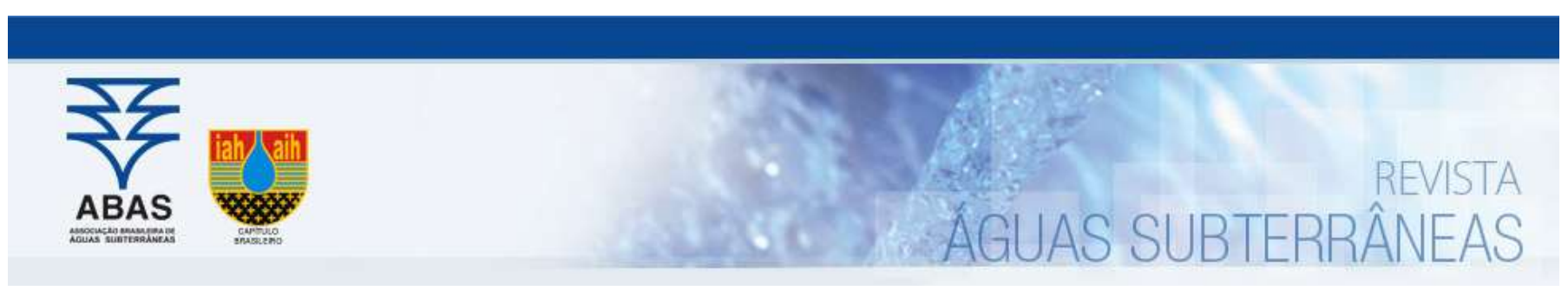

Artigos

\title{
Análise multivariada dos parâmetros de qualidade das águas subterrâneas em Juazeiro do Norte - CE (Brasil)
}

\author{
Multivariate analysis of underground water quality parameters in Juazeiro do \\ Norte - CE (Brasil)
}

\section{Raimunda Moreira da Franca1; Maria da Conceição Rabelo Gomes¹; Fernando José Araújo da Silva1; Maria Gorethe de Sousa Lima2; Horst Frischkorn ${ }^{1 凶}$}

1 Universidade Federal do Ceará (UFC), Fortaleza, CE

2 Universidade Federal do Cariri (UFCa), Juazeiro do Norte, CE

\francacariri@yahoo.com.br, conceicaorabelo@yahoo.com.br, fjas@deha.ufc.br, gorethe.lima@ufca.edu.br, cariri@ufc.br

\section{Resumo}

Palavras-chave:

Físico-químicas.

Análise fatorial.

Análise de agrupamento.

Semiárido.

Poços.

\begin{abstract}
O município de Juazeiro do Norte tem como fonte hídrica, o manancial subterrâneo, sendo considerado a única fonte de abastecimento público e privado da área. No entanto a superexplotação já é comprovada na intermitência da antiga rede de drenagem perene, hoje perenizada por lançamentos de esgotos domésticos. Diante deste cenário, objetivou-se aplicar a análise multivariada nos parâmetros de qualidade da água subterrânea em Juazeiro do Norte, Ceará, através da técnica da análise fatorial, associada a análise de agrupamento hierárquico. Para fins de avaliação considerou-se 13 parâmetros oriundos de 11 poços tubulares: condutividade elétrica, pH, oxigênio dissolvido, turbidez, cor, nitrato, amônia, alcalinidade, dureza total, cloreto, sulfato, ferro total e sólidos totais dissolvidos, os quais foram mensurados em dois momentos, período seco (novembro/2002) e período chuvoso (abril/2003). Os resultados da análise fatorial apresentaram dois fatores, tanto para o período seco, quanto para o chuvoso, com autovalores superiores a um, indicando o total da variância causado por cada fator. A análise de agrupamento multivariada, aplicada aos parâmetros do primeiro fator nos dois períodos, apresentou dendrogramas com formação de três grupos. Enquanto os parâmetros do segundo fator apresentaram 3 e 2 grupos para os períodos seco e chuvoso, respectivamente.
\end{abstract}

\section{Abstract}

The municipality of Juazeiro do Norte has as its source the underground spring, being considered the only source of public and private supply of the area. However, overexploitation is already proven in the intermittency of the old perennial drainage network, now perpetuated by releases of domestic sewage. The objective of this work was to apply the multivariate analysis to groundwater quality parameters in Juazeiro do Norte, Ceará, through the technique of factorial analysis, associated with multivariate cluster analysis. For evaluation purposes, 13 parameters from 11 tubular wells were studied: electrical conductivity, pH, dissolved oxygen, turbidity, color, nitrate, ammonia, alkalinity, total hardness, chloride, sulfate, total iron and total dissolved solids, measured in two moments, dry period (November/2002) and rainy season (April/2003). The results of the factorial analysis presented two factors, both for the dry period and for the rainy season, with eigenvalues greater than one, indicating the total of the variance caused by each factor. Multivariate cluster analysis, applied to the parameters of the first factor in both periods, presented dendrograms with formation of three groups. While the parameters of the second factor presented 3 and 2 groups for the dry and rainy periods, respectively.

\section{INTRODUÇÃO}

As águas subterrâneas constituem recurso estratégico e de vital importância para a região do Cariri, na porção sul do Estado do Ceará, Nordeste do Brasil. Nesta, a sustentação socioeconômica e o desenvolvimento dependem inteiramente da explotação dessas águas, seja por meio de poços profundos, rasos ou fontes naturais. Dentre os municípios desta região, destaca-se Juazeiro do Norte, sede da Região Metropolitana com mesmo nome, com- posta de mais oito municipalidades. 0 município tem caráter quase que inteiramente urbano e o manancial subterrâneo é sua única fonte de abastecimento d'água para suprir aos diferentes fins (i.e. consumo humano, serviços, indústria e lazer).

No Cariri cearense, e principalmente em Juazeiro do Norte, o incremento das pressões antrópicas sobre os recursos hídricos subterrâneos vem causando apreensão crescente. Isto vem se dando não apenas pelo crescimento populacional, mas principal- 
mente pelo desenvolvimento e diversificação das atividades poluidoras. Portanto, as águas subterrâneas na região do Cariri encontram-se ameaçadas tanto no aspecto quantitativo quanto no qualitativo.

Para avaliar a qualidade das águas subterrâneas é necessário a realização de análises físico-químicas, que produzam resultados de diversas variáveis, apresentando característica multivariada, deixando clara a necessidade do tratamento multivariado dos dados. Segundo Vicini (2005), a análise multivariada é um conjunto de procedimentos estatísticos que permite avaliar simultaneamente diversas variáveis de uma amostra ou população.

Agresti e Finlay (2012) esclarecem que a análise multivariada compreende técnicas estatísticas que analisam simultaneamente múltiplas medidas sobre indivíduos ou objetos de investigação. Podem ser consideradas extensões ou complementos das análises univariadas ou bivariadas. Uma das maiores vantagens em se utilizar a análise multivariada é que os usos de métodos analíticos mais sofisticados permitem fazer interpretações de fenômenos e previsões melhores que modelos uni e bivariáveis.
Permite-se ainda analisar relações entre variáveis, enquanto se controlam outras. Estudos utilizando essa ferramenta foram desenvolvidos por Vega et al. (1998); Andrade et al. (2008); Fernandes et al. (2010); Salgado et al. (2011); Gomes e Cavalcante (2017).

Na região do Cariri, estudos sobre a qualidade das águas subterrâneas quanto à poluição das mesmas ainda são limitados. Neste esteio presente trabalho teve por objetivo aplicar a análise multivariada nos parâmetros de qualidade da água subterrânea em Juazeiro do Norte, Ceará, através da técnica da análise fatorial, associada a análise de agrupamento hierárquico, auxiliando na definição de quais variáveis são mais importantes para a subsidiar a gestão qualitativa das águas na área.

\section{CARACTERIZAÇÃO DA ÁREA}

A área de estudo envolve parte do município de Juazeiro do Norte situado ao sul do Estado do Ceará, no Vale do Cariri, sob as coordenadas geográficas $7^{\circ} 12^{\prime} 47^{\prime \prime}$ de latitude sul e $39^{\circ} 18^{\prime} 55^{\prime \prime}$ de longitude oeste, e possui uma área de $15,8 \mathrm{~km}^{2}$ (Figura 1).

Figura 1 - Carta temática das unidades geológicas com a localização dos pontos de coleta, ao longo do riacho dos Macacos, em Juazeiro do Norte - CE

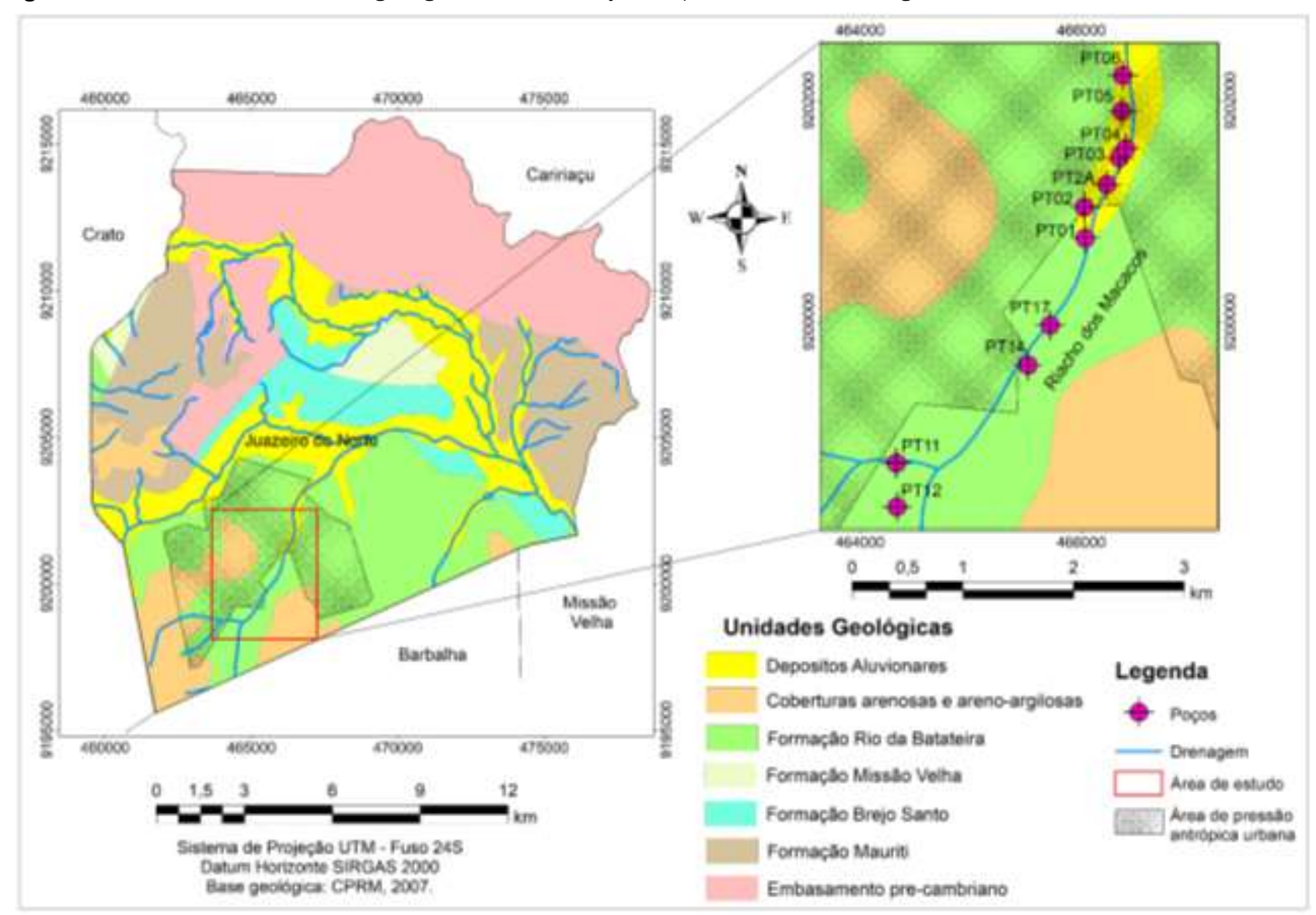

Juazeiro do Norte está inserido na bacia hidrográfica do Salgado, e apresenta como principais drenagens o riacho dos Macacos e o rio Salgado. Segundo o último censo (IBGE, 2010), Juazeiro do Norte é a maior cidade do interior cearense em aspecto de desenvolvimento, com população de 268.248 mil habitantes (densidade de $1.005 \mathrm{hab} / \mathrm{Km}^{2}$ ), com taxa de urbanização de 95,3\%. Ressalta-se que a área de estudo apresenta $64,5 \%$ de área urbanizada.
Geologicamente a área é constituída por rochas do embasamento pré-cambriano e rochas sedimentares pertencentes à Bacia Sedimentar do Araripe (CPRM, 2000). As rochas sedimentares são formadas do topo para a base, por depósitos aluvionares, coberturas arenosas, Formação Rio da Batateira, Formação Missão Velha, Formação Brejo Santo e a Formação Mauriti (Figura 1). 
Na área aflora e predomina a Formação Rio da Batateira, caracterizada por arenitos argilosos médios a finos, com espessura média de $200 \mathrm{~m}$, associado com a presença de depósitos aluvionares. Esta constitui o aquífero livre explotado mais importante, sendo afetado pela ausência de controle na exploração dos poços e a precariedade de saneamento básico. A área de influência da principal bateria de poços foi transformada em pequenos lixões, e o riacho dos Macacos está hoje servindo de canal para esgotos domésticos dos bairros vizinhos.

Segundo Cabral (1997), no município de Juazeiro do Norte são produzidas diariamente 291 toneladas de lixo, depositadas em terrenos baldios e lixões a céu aberto, constituindo-se em ameaças aos mananciais hídricos da área.

Com base na população de 268.248 mil habitantes e apenas $38,20 \%$ atendidos por serviços de esgotamento sanitário (CAGECE, 2003) tem-se que 173.583 habitantes não dispõem de coleta de esgoto, considerando a carga de $4 \mathrm{~kg} \mathrm{~N}-\mathrm{NO}_{3}$ / $/ \mathrm{hab} / \mathrm{ano}$. Estima-se que 694,332kg $\mathrm{NNO}_{3}$ /ano são lançados nos corpos d'água no município (FRANCA, 2004).
A área de estudo compreende o Parque Ecológico das Timbaúbas que apresenta vegetação parcialmente degradada. Desmatamentos e queimadas são atividades praticadas constantemente no município. A mata ciliar que compõe as margens do riacho dos Macacos encontra-se descaracterizada pela ação antrópica. No inverno, a Várzea da Timbaúba torna-se favorável à vegetação hidrófila. Nas águas do riacho dos Macacos encontram-se macrófitas durante a estação chuvosa, em especial o Aguapé (Eichornia crassipes), que é um indicativo de possível poluição. Outras plantas aquáticas não foram identificadas por falta de estudos sistemáticos na região.

O regime pluviométrico em Juazeiro do Norte apresenta variações temporais espaciais, com a repartição das chuvas dentro do ano concentradas num período de 5 a 6 meses em média (dezembro a maio). De acordo com a FUNCEME (2004), a precipitação anual em 2002 atingiu 1.266,5mm com chuvas máximas de $431 \mathrm{~mm}$ em janeiro e 325,5mm em março. Já em 2003 atingiu $1.350 \mathrm{~mm}$ durante todo o ano, com chuvas máximas de $282 \mathrm{~mm}$ em janeiro e $495 \mathrm{~mm}$ em março. De acordo com a figura 2 , observava-se uma distribuição bimodal nas precipitações.

Figura 2 - Precipitação mensal durante os anos de 2002 e 2003 no município de Juazeiro do Norte-CE

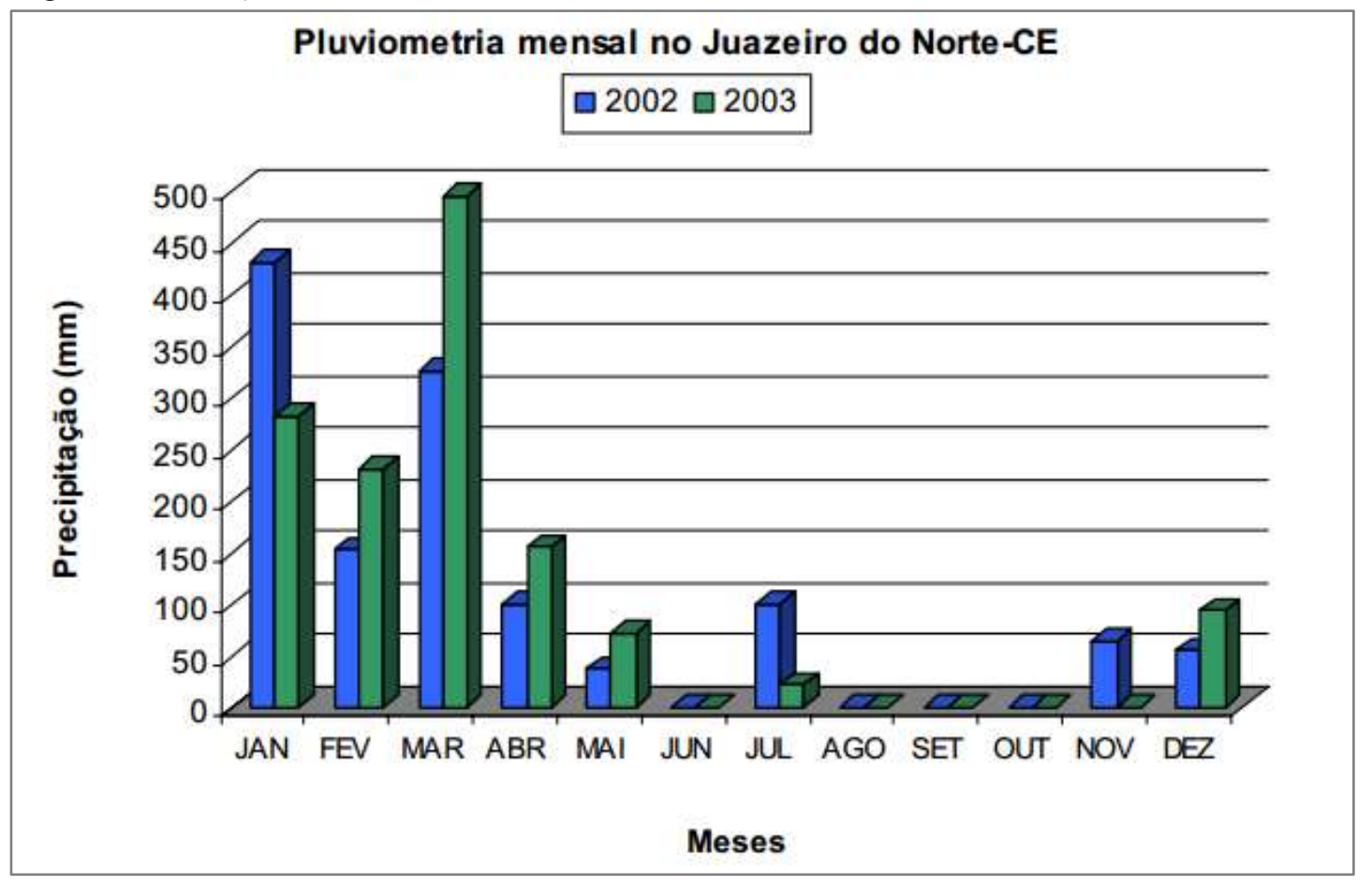

\section{MATERIAIS E MÉTODOS}

0 estudo foi referente a 11 poços tubulares localizados ao longo da linha de talvegue do riacho dos Macacos (Figura 1). As amostras de água foram coletadas em dois momentos distintos do ciclo de precipitação anual, a saber: período seco (novembro/2002) e período chuvoso (abril/2003).

Nas amostras foram determinados os seguintes parâmetros físico-químicos de qualidade da água: condutividade elétrica (CE), potencial hidrogeniônico $(\mathrm{pH})$, oxigênio dissolvido $(\mathrm{OD})$, turbidez $\left(\mathrm{T}_{\mathrm{B}}\right)$, cor, nitrato $\left(\mathrm{N}^{-\mathrm{NO}_{3}}{ }^{-}\right.$), amônia ( $\left.\mathrm{N}-\mathrm{NH}_{3}\right)$, alcalinidade (Alc), dureza total $\left(\mathrm{D}_{\mathrm{T}}\right)$, cloreto $\left(\mathrm{Cl}^{-}\right)$, sulfato $\left(\mathrm{SO}_{4}{ }^{2-}\right)$, ferro total $(\mathrm{Fe})$ e sólidos totais dissolvidos (STD). Os procedimentos analíticos seguiram os métodos descritos em APHA (1998).

Foram aplicadas duas técnicas de análise multivariada: análises fatorial e de agrupamento hierárquico. A análise fatorial explica a correlação ou covariância, entre o conjunto de variáveis, em termos de um número limitado de variáveis não-observáveis. Essas variáveis não-observáveis ou fatores são calculados pela combinação linear das variáveis originais.

A análise fatorial utilizou-se o método da análise da componente principal (ACP), com emprego da rotação varimax normalizada. 0 objetivo deste procedimento é descrever as relações de covariân- 
cia entre os parâmetros correlacionados, tendo como base os fatores identificados, além de evidenciar, através das comunalidades, o quanto cada parâmetro explica cada fator (MANLY, 1998). A verificação da adequação dos dados da análise fatorial realizou-se a partir do índice KMO (Kaiser-Meyer-Olkin Measure of Sampling Adequacy) e do Teste Estatístico de Esfericidade de Bartlett, que testa a hipótese nula de que as variáveis analisadas não são correlacionadas (HAIR JR. et al., 1998; ARAÚJO et al., 2013).

Por fim, realizou-se o agrupamento hierárquico das amostras a partir do maior número de parâmetros explicados por um único fator da análise fatorial. Nessa técnica, utilizou-se o método Ward como critério hierárquico de agrupamento, com medida de similaridade dada pela distância euclidiana quadrada (Squared Euclidean Distance). Esse critério de agrupamento utiliza a soma total dos quadrados dos desvios de cada objeto em relação à média do grupo onde o mesmo foi inserido. A escolha deste critério se fundamentou na frequente empregabilidade do mesmo em estudos de qualidade da água (VEGA et al., 1998; ANDRADE et al, 2008; FERNANDES et al., 2010; SALGADO et al, 2011; GOMES e CAVALCANTE, 2017).

Essas análises estatísticas foram processadas no software SPSS Statistics, versão 17.0.

A partir dos grupos formados, a avaliação da adequação das águas subterrâneas para consumo humano foi feita conforme o padrão de potabilidade da Portaria № 2914 de 12/12/2011 do Ministério da Saúde (BRASIL, 2011).

\section{RESULTADOS E DISCUSSÃO}

Aplicaram-se três simulações, na primeira simulação utilizou-se todo o conjunto de parâmetros físico-químicos na análise fatorial. Os índices KMO obtidos para o conjunto, nos períodos seco e chuvoso, foram respectivamente 0,260 e 0,208 e os testes estatísticos de esfericidade de Bartlett não se mostraram significativos a $p<0,01$, ou seja, as variáveis analisadas não são correlacionadas.

Esses resultados indicaram que os fatores encontrados na análise fatorial não descreveram adequadamente a variação dos dados originais. Nesse contexto, três dos 13 parâmetros analisados (STD, $\mathrm{Fe}$ e $\mathrm{SO}_{4}{ }^{2-}$ ) apresentaram baixa comunalidade (i.e. inferior a 0,600 ), indicando a baixa explicação de cada parâmetro em cada fator.

Na segunda simulação foram empregados os 10 parâmetros restantes. Verificou-se que os índices KMO permaneceram baixos para ambos os períodos e os testes estatísticos de esfericidade de Bartlett continuaram sem significância. Nessa simulação, três dos parâmetros restantes ( $\mathrm{pH}$, alcalinidade e OD) continuaram apresentando baixa comunalidade.

Na terceira simulação, os três parâmetros que apresentaram baixa comunalidade foram desconsiderados e os modelos apresentaram resultados favoráveis para sete parâmetros no período seco (CE, $\mathrm{T}_{\mathrm{B}}$, cor, $\mathrm{N}_{-} \mathrm{NO}_{3}, \mathrm{~N}_{-} \mathrm{NH}_{3}$, Di e cloreto) e seis no período chuvoso (com exceção de $\mathrm{N}-\mathrm{NH}_{3}$ ), com índices $\mathrm{KMO}$ de respectivamente 0,682 e 0,649, para os períodos seco e chuvoso e testes de esfericidade de Bartlett significativos a $p<0,01$.

Os resultados da análise fatorial apresentaram dois fatores, tanto para o período seco, quanto para o chuvoso, com autovalores superiores a um, indicando o total da variância causado por cada fator (Tabela 1).

Tabela 1 - Cargas fatoriais, comunalidades e variância explicada na análise fatorial dos parâmetros físico-químicos de qualidade de água analisados em duas condições climáticas, após a rotação pelo método varimax Parâme- Período seco (novembro/ 2002) Período chuvoso (abril/ 2003) tro

Carga Fatorial

\begin{tabular}{|c|c|c|c|c|c|c|}
\hline & \multicolumn{2}{|c|}{ Carga Fatorial } & \multirow{3}{*}{ Comunalidade } & \multicolumn{2}{|c|}{ Carga Fatorial } & \multirow{3}{*}{ Comunalidade } \\
\hline & Fa- & Fator & & Fator & Fator & \\
\hline & tor 1 & 2 & & 1 & 2 & \\
\hline \multirow[t]{2}{*}{ CE } & - & 0,921 & 0,914 & 0,799 & - & 0,735 \\
\hline & 0,257 & & & & ,0312 & \\
\hline \multirow[t]{2}{*}{$\mathrm{T}_{\mathrm{B}}$} & 0,9 & - & 0,957 & - & 0,981 & 0,978 \\
\hline & 77 & 0,041 & & 0,124 & & \\
\hline \multirow[t]{2}{*}{ Cor } & 0,9 & - & 0,969 & - & 0,965 & 0,965 \\
\hline & 26 & 0,336 & & 0,184 & & \\
\hline \multirow[t]{2}{*}{$\mathrm{N}-\mathrm{NO}_{3}-$} & - & - & 0,650 & 0,887 & 0,039 & 0,788 \\
\hline & 0,676 & 0,019 & & & & \\
\hline \multirow[t]{2}{*}{$\mathrm{N}-\mathrm{NH}_{3}$} & 0,9 & - & 0,962 & - & & \\
\hline & 12 & 0,362 & & & - & - \\
\hline \multirow[t]{2}{*}{ DT } & - & 0,792 & 0,934 & 0,896 & - & 0,916 \\
\hline & 0,553 & & & & 0,337 & \\
\hline \multirow[t]{2}{*}{$\mathrm{Cl}^{-}$} & 0,1 & 0,920 & 0,860 & 0,840 & - & 0,714 \\
\hline & 11 & & & & 0,096 & \\
\hline Variância & 62,1 & 2434 & - & 5906 & 2588 & 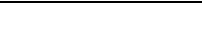 \\
\hline explicada (\%) & 4 & 24,34 & - & 59,00 & 25,80 & - \\
\hline $\begin{array}{r}\text { Variância } \\
\text { acumulada (\%) }\end{array}$ & & & - & & & - \\
\hline
\end{tabular}

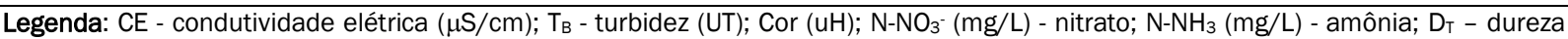
total (mg/L de $\left.\mathrm{CaCO}_{3}\right) ; \mathrm{Cl}^{-}(\mathrm{mg} / \mathrm{L})$ - cloretos 
Para o período seco, o primeiro fator apresentou uma contribuição para explicação da variância total do conjunto amostral de aproximadamente $62 \%$, mostrando uma alta correlação entre os parâmetros turbidez, cor, $\mathrm{N}^{-\mathrm{NO}_{3}}$ e N-NH . $\mathrm{Na}$ área é comum o lançamento de efluentes não tratados em rios e riachos, introduzindo segundo Lucena et al. (2004), quantidades elevadas de carbono orgânico solúvel, nitrogênio, cloretos, potássio e magnésio nas águas superficiais, que por conexão hidráulica entre o lençol freático e o leito de drenagem dos corpos d'águas são capazes de atingir os aquíferos. Franca et al. (2006), observaram em uma bateria de poços que abastece a cidade de Juazeiro do Norte que as águas explotadas por parte dos poços apresentaram indícios de poluição por esgotos domésticos. A alta correlação de turbidez e cor indicam uma forte influência antropogênica na composição dessa água.

Já no período chuvoso, o primeiro fator corresponde a $59 \%$ de toda variância do conjunto amostral, representado por $\mathrm{CE}, \mathrm{N}-\mathrm{NO}_{3}{ }^{-}$ , dureza total e cloreto. Observa-se que a amônia $\left(\mathrm{N}-\mathrm{NH}_{3}\right)$ não aparece como parâmetro, indicando uma possível oxidação do mesmo para nitrato ( ${\mathrm{N}-\mathrm{NO}_{3}}^{-}$), do período seco para o chuvoso. Segundo Gomes e Cavalcante (2017), a recarga nas áreas antropizadas seria uma possível fonte de contaminação recente. 0 $\mathrm{NO}_{3}$ - tem alta mobilidade nos sistemas aeróbios de águas subterrâneas, como em aquíferos onde os níveis estáticos encontramse pouco profundos ou as condutividades hidráulicas são relativamente elevadas. Nestes meios, o $\mathrm{NO}_{3}-$ move-se sem retardamento, podendo atingir extensas áreas.
O segundo fator para o período seco, corresponde a $24 \%$ de toda a variância do conjunto amostral, mostrando uma alta correlação entre $\mathrm{CE}$, dureza total $\left(\mathrm{CaCO}_{3}\right)$ e cloreto.

Enquanto no período chuvoso, o fator 2 corresponde a $26 \%$ de toda variância do conjunto amostral, representado pela turbidez e cor. A correlação forte entre turbidez e cor ocorre devido ao baixo mecanismo de diluição na amostra coletada e/ou também pela ausência de proteção sanitária dos poços, o que permite a entrada de impurezas, aumentando a turbidez das águas e consequentemente influenciando na cor. Resultados semelhantes foram encontrados por Andrade et al. (2007).

A técnica de análise de agrupamento, aplicada aos parâmetros explicados pelos fatores 1 e 2 da análise fatorial, agrupou as amostras com características semelhantes quimicamente (Figuras 3 e 4). 0 número de grupos foi definido pela primeira grande diferença entre os coeficientes reescalonados de agrupamento. Esses coeficientes explicitaram o ponto de corte cinco, onde observou-se a formação de três grupos homogêneos para o período seco em cada fator. Enquanto no período chuvoso foram formados três grupos homogêneos para o primeiro fator e dois grupos para o segundo fator.

Os parâmetros do fator 1 geraram 3 grupos similares nos períodos seco (novembro/ 2002) e chuvoso (abril/ 2003) (Figura 3 A e B).

Figura 3 - Dendrogramas resultante da análise de agrupamento hierárquico das variáveis explicadas no Fator 1 (A - período seco e B - período chuvoso)

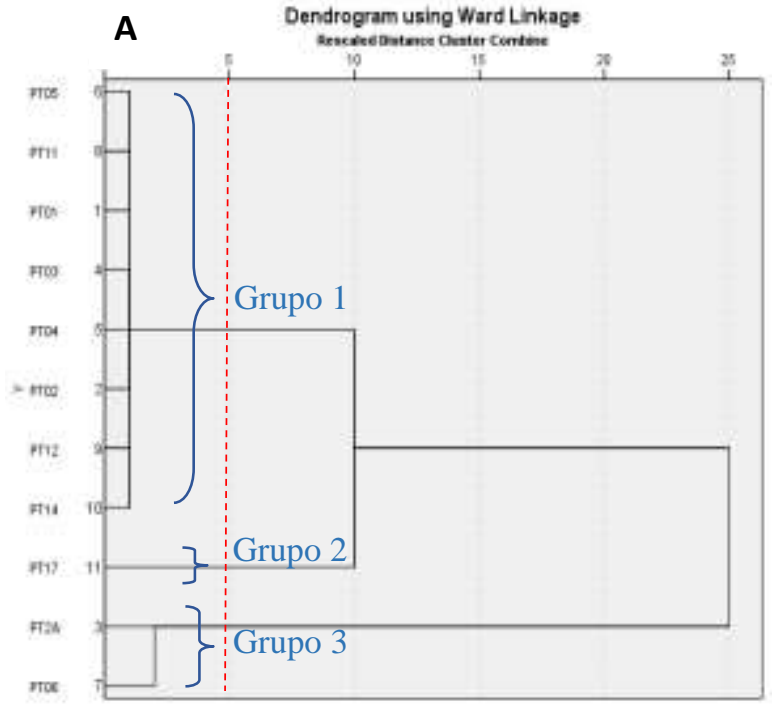

0 grupo 1 do fator 1 foi formado por respectivamente 73 (8 poços) e $36 \%$ (4 poços) das amostras analisadas nos períodos seco e chuvoso (Figura 3 ).

No período seco, 100\% das amostras do grupo 1 (8 poços) atendem aos padrões de potabilidade definidos na Portaria $\mathrm{N}^{\circ}$ 2914/2011 do Ministério da Saúde quanto a concentração de

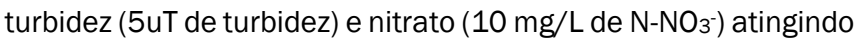
no máximo 0,3 uT (PT12) e 8,9 mg/L (PT03), respectivamente. Nesse grupo, $75 \%$ das amostras ( 6 poços) apresentaram concentrações de amônia acima do valor máximo permissível $(1,5 \mathrm{mg} / \mathrm{L}$

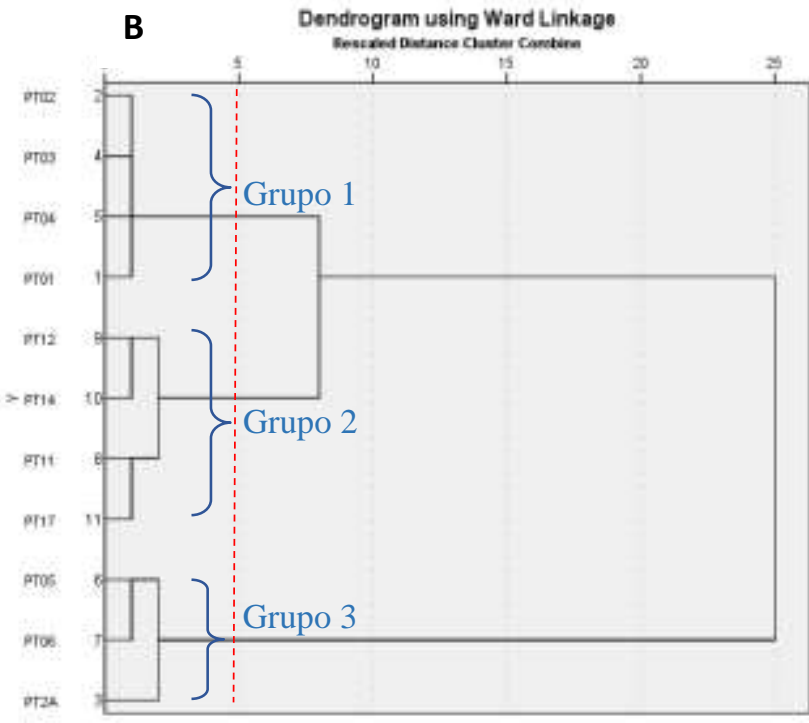

de $\mathrm{N}-\mathrm{NH}_{3}$ ), atingindo até $4,30 \mathrm{mg} / \mathrm{L}$ (PT05). Esses poços explotam o aquífero Rio da Batateira e proximidades de aluviões, com profundidade variando de 140 (PT03) a $160 \mathrm{~m}$ (PT05). A cor das águas analisadas variou de 1,0 (PT03 e PT05) a 3,0 uH (PT01). Segundo Santos (2008), comumente, as águas subterrâneas apresentam valores de coloração inferiores a $5 \mathrm{uH}$. Geralmente, para ser potável, uma água não deve apresentar nenhuma cor de considerável intensidade.

No período chuvoso, o grupo 1 (4 poços) foi caracterizado por águas de salinidade intermediária $(290 \mu \mathrm{S} / \mathrm{cm} \leq \mathrm{CE} \leq 312$ 
$\mu \mathrm{S} / \mathrm{cm})$. As concentrações de cloreto e dureza total atingiram no máximo $44,1 \mathrm{mg} / \mathrm{L}$ e $138,0 \mathrm{mg} / \mathrm{L}$, respectivamente, ambos no PT04 (profundidade de $140 \mathrm{~m}$ ), estando dentro do valor máximo permissível pela Portaria № 2914/2011 do Ministério da Saúde ( $250 \mathrm{mg} / \mathrm{L}$ de cloreto e $500 \mathrm{mg} / \mathrm{L}$ de dureza), corroborando com os resultados de Fernandes et al. (2010). Das 4 amostras, duas apresentaram concentração de nitrato acima do valor máximo permissivel (10 mg/L de N-NO3), com valores de 11,5 (PT02 com profundidade de $150 \mathrm{~m}$ ) e 19,6 mg/L (PT03 com profundidade de $140 \mathrm{~m})$.

Já o grupo 2 do fator 1 foi constituído por 9 (1 poço) e $36 \%$ (4 poços) das amostras analisadas nos períodos seco e chuvoso, respectivamente (Figura 3).

No período seco, a amostra do grupo 2 (PT17 com profundidade de $82 \mathrm{~m}$ ) atende aos padrões de potabilidade definidos na Portaria $N^{\circ} 2914 / 2011$ do Ministério da Saúde quanto a concentração de turbidez (5 uT de turbidez), nitrato (10 mg/L de N-NO $3_{3}^{-}$) e amônia (1,5 mg/L de N-NH 3 ), com valores de 4,0 uT, 2,3 mg/L e $0,98 \mathrm{mg} / \mathrm{L}$, respectivamente. A cor da água é de 33,0 uH. A Portaria $N^{\circ}$ 2914/2011 do Ministério da Saúde estabelece um valor máximo permissível de 15 uH para a cor aparente.

No período chuvoso, o grupo 2 (4 poços) foi caracterizado pelas baixas concentrações de sais $(126 \mu \mathrm{S} / \mathrm{cm} \leq \mathrm{CE} \leq 210 \mu \mathrm{S} / \mathrm{cm})$ e deteve águas de melhor qualidade. As concentrações de cloreto e dureza atingiram no máximo 13,8 (PT11 - 90 m de profundidade) e 108,0 mg/L (PT14 - $154 \mathrm{~m}$ de profundidade), respectivamente, estando os valores dentro do valor máximo permissível (VMP) pela Portaria № 2914/2011 do Ministério da Saúde (250 $\mathrm{mg} / \mathrm{L}$ de cloreto e $500 \mathrm{mg} / \mathrm{L}$ de dureza total). As 4 amostras apresentaram concentração de nitrato dentro das normas da potabilidade $\left(10 \mathrm{mg} / \mathrm{L}\right.$ de $\mathrm{N}^{-\mathrm{NO}_{3}}{ }^{-}$), atingindo no máximo $3,7 \mathrm{mg} / \mathrm{L}$ (PT14).

0 grupo 3 do fator 1 foi composto por respectivamente 18 (2 poços) e $27 \%$ ( 3 poços) das amostras analisadas nos períodos seco e chuvoso (Figura 3 ).

No período seco, as duas amostras do grupo 3 (PT2A sem informação da profundidade e PT06 com profundidade de $190 \mathrm{~m}$ ) atendem aos padrões de potabilidade definidos na Portaria $\mathrm{N}^{\circ}$ 2914/2011 do Ministério da Saúde quanto a concentração de turbidez (5 uT de turbidez), nitrato (10 mg/L de N-NO $3^{-}$), amônia $\left(1,5 \mathrm{mg} / \mathrm{L}\right.$ de $\left.\mathrm{N}-\mathrm{NH}_{3}\right)$ e cor (15 uH). As amostras dos poços PT2A e PT06 apresentaram concentrações de turbidez de 1,6 e 0,25 uT, nitrato de 4,2 e 3,5 mg/L, amônia de 2,8 e 2,9 mg/L e cor de 3,0 e $1,0 \mathrm{uH}$, respectivamente.

No período chuvoso, o grupo 3 (3 poços) foi caracterizado por águas de maior salinidade $(419 \mu \mathrm{S} / \mathrm{cm} \leq \mathrm{CE} \leq 490 \mu \mathrm{S} / \mathrm{cm})$ e deteve águas de menor qualidade. As concentrações de cloreto e dureza total atingiram no máximo 59,8 e 190,0 mg/L, respectivamente, ambos no poço PT2A, estando os valores dentro do vaIor máximo permissivel pela Portaria № 2914/2011 do Ministério da Saúde (250 mg/L de cloreto e $500 \mathrm{mg} / \mathrm{L}$ de dureza). Das 3 amostras, duas apresentaram concentração de nitrato acima do valor máximo permissivel (10 mg/L de $\left.\mathrm{N}^{-\mathrm{NO}_{3}}{ }^{-}\right)$, atingindo no máximo $24,8 \mathrm{mg} / \mathrm{L}_{\text {de }} \mathrm{N}^{-\mathrm{NO}_{3}}{ }^{-}$(PT2A).

Os parâmetros do fator 2 geraram 3 grupos no período seco (novembro/ 2002) e 2 grupos no chuvoso (abril/ 2003) (Figura 4 C e D).

Figura 4 - Dendrogramas resultante da análise de agrupamento hierárquico das variáveis explicadas no Fator 2 (C - período seco e D período chuvoso)
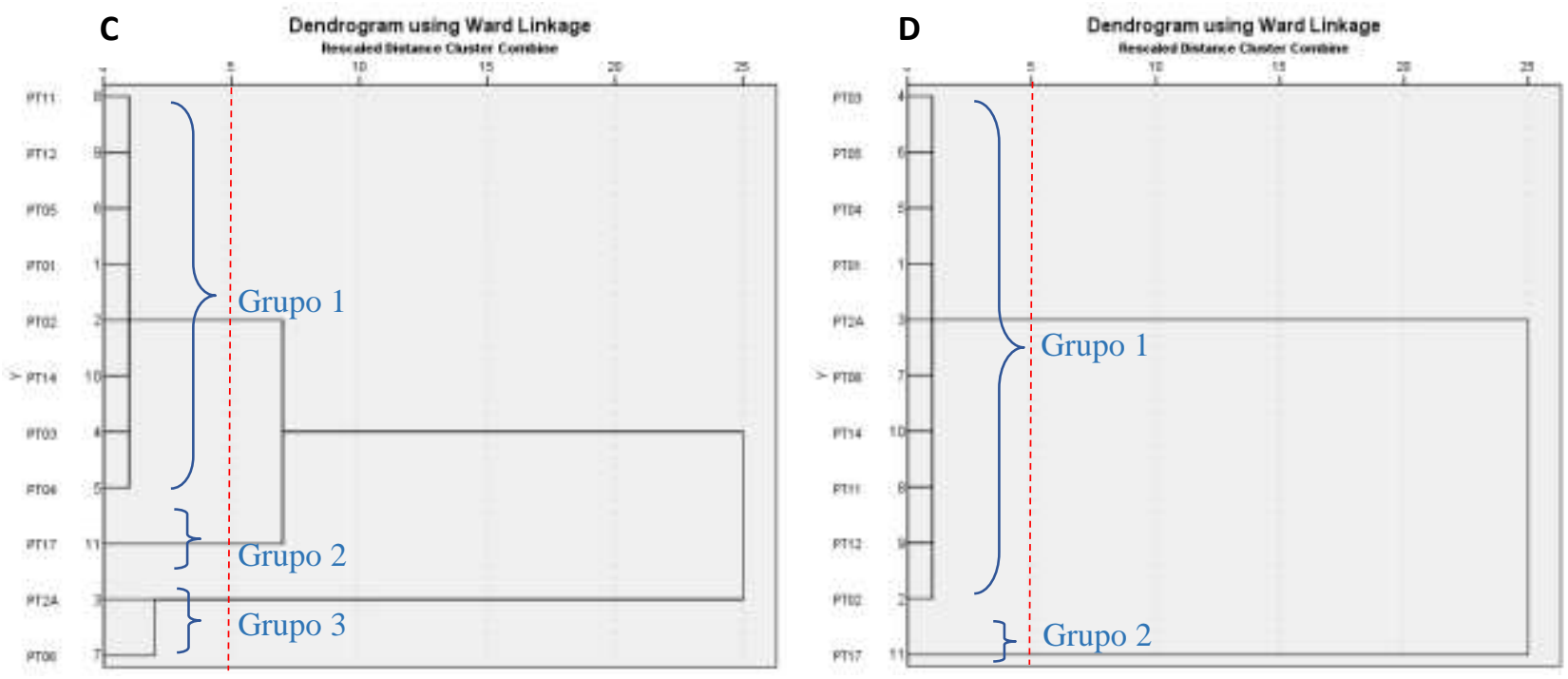

0 grupo 1 do fator 2 foi composto por respectivamente 73 (8 poços) e $91 \%$ (10 poços) das amostras analisadas nos períodos seco e chuvoso (Figura 4).

No período seco, o grupo 1 permaneceu com as 8 amostras agrupadas anteriormente no fator 1 (grupo 1) e explotam águas de

salinidade intermediária (305 $\mu \mathrm{S} / \mathrm{cm} \leq \mathrm{CE} \leq 385 \mu \mathrm{S} / \mathrm{cm})$. As concentrações de cloreto e dureza total atingiram no máximo 30,2 (PT02 com profundidade $150 \mathrm{~m}$ ) e $113 \mathrm{mg} / \mathrm{L}$ (PT11 com profundidade de $90 \mathrm{~m}$ ), estando ambos dentro do valor máximo permissível pela Portaria N ${ }^{\circ}$ 2914/2011 do Ministério da Saúde (250 $\mathrm{mg} / \mathrm{L}$ de cloreto e $500 \mathrm{mg} / \mathrm{L}$ de dureza total). Esse resultado foi 
comentado também por Fernandes et al. (2010).

No período chuvoso, as dez amostras do grupo 1 atendem aos padrões de potabilidade quanto a concentração de turbidez (VMP de 5 uT) e cor (VMP de 15 uH). A turbidez variou de 0,27 (PT01 com profundidade de $110 \mathrm{~m}$ ) a 2,30 uT (PT2A sem informação da profundidade). A cor das águas variou de 1,0 (PT01) a 3,5 uH (PT2A), mostrando a correlação forte entre esses dois parâmetros.

Enquanto o grupo 2 do fator 2 apresentou 9\% (1 poço) das amostras analisadas nos períodos seco e chuvoso (Figura 4).

No período seco, o grupo 2 representado pelo poço PT17 (profundidade de $82 \mathrm{~m}$ ) explota águas menos mineralizadas do aquífero Rio da Batateira, com CE, dureza total e cloreto de 170 $\mu \mathrm{S} / \mathrm{cm}, 28 \mathrm{mg} / \mathrm{L}$ e $8,8 \mathrm{mg} / \mathrm{L}$, respectivamente, estando os valores dentro das normas de potabilidade (Portaria № 2914/2011 do Ministério da Saúde).

No período chuvoso, a amostra do poço PT17 permaneceu no grupo 2 e não atendeu ao padrão de potabilidade quanto a concentração de turbidez (VMP de 5 uT) e cor (VMP de 15 uH), atingindo 9,2 uT de turbidez e 23 uH de coloração da água. Ressaltando que das 11 amostras analisadas, o poço PT17 foi o que obteve a maior concentração de turbidez e cor, mostrando novamente segundo Andrade et al. (2007), a correlação forte entre esses dois parâmetros.

O grupo 3 do fator 2 foi composto por $18 \%$ (2 poços) das amostras analisadas no período seco, sendo ausente no período chuvoso (Figura 4).

No período seco, o grupo 3 (2 poços) explota águas mais mineralizadas $(549 \mu \mathrm{S} / \mathrm{cm} \leq \mathrm{CE} \leq 630 \mu \mathrm{S} / \mathrm{cm})$. As concentrações de cloreto e dureza atingiram no máximo 71,0 e 144,0 mg/L, ambos no poço PT2A (sem informação da profundidade), estando dentro do valor máximo permissível pela Portaria № 2914/2011 do Ministério da Saúde $(250 \mathrm{mg} / \mathrm{L}$ de cloreto e $500 \mathrm{mg} / \mathrm{L}$ de dureza total).

\section{CONSIDERAÇÕES FINAIS}

A análise fatorial aplicada a parâmetros físico-químicos de qualidade das águas subterrâneas, nos períodos seco e chuvoso, mostrou que os dois fatores respondem por aproximadamente 86 e $85 \%$ da variância total dos dados, respectivamente.

A análise de agrupamento multivariada, aplicada aos parâmetros do primeiro fator da análise fatorial nos dois períodos, apresentou dendrogramas com formação de três grupos. Enquanto os parâmetros do segundo fator apresentaram 3 e 2 grupos para os períodos seco e chuvoso, respectivamente.

Os dendrogramas gerados pelo agrupamento dos parâmetros do primeiro fator apresentaram-se distintos no período seco e chuvoso. No primeiro caso como indicador de elementos nitrogenados (ação antrópica) e o segundo como indicador de salinidade e elementos nitrogenados (ação antrópica) nas águas subterrâneas.
Os dendrogramas gerados pelo agrupamento do segundo fator indicaram três tipos de água para o período seco. Os Grupos 1, 2 e 3 são caracterizados por águas de salinidade intermediária, baixa e alta, respectivamente. A concentração de sais nas águas pode ser produzida por diversos fatores, sendo os mais prováveis a dissolução e o processo de evaporação. 0 agrupamento para o período chuvoso indica substâncias dissolvidas ou em suspensão na água, provenientes, principalmente, da lixiviação da matéria orgânica.

A análise multivariada mostrou ser uma ferramenta de suporte ao monitoramento e gestão da qualidade das águas no semiárido, em agrupar amostras quimicamente similares pelos valores de suas concentrações.

No geral, o uso das técnicas multivariadas contribui para uma melhor qualidade das pesquisas científicas, proporcionando uma economia relativa de tempo e de custo, e facilitando a interpretação das estruturas dos dados, diminuendo a perda de informação.

\section{REFERÊNCIAS}

AGRESTI, A.; FINLAY, B. Métodos estatísticos para as ciências sociais. Porto Alegre. Penso, 664 p., 2012.

ANDRADE, E. M.; ARAÚJO, L. F. P.; ROSA, M. F.; DISNEY, ALVES, W.; A. B. Seleção dos indicadores da qualidade das águas superficiais pelo emprego da análise multivariada. Revista Engenharia Agrícola, v. 27, n. 3, p. 683-690, 2007.

ANDRADE, E. M.; PALÁCIO, H. A.; SOUZA I.H.; OLIVEIRA L. R. A.; GUERREIRO, M.J. Land use effects in groundwater composition of an alluvial aquifer (Trussu River, Brazil) by multivariate techniques. Environmental Research, v. 106, n. 2, p. 170-177, 2008.

APHA. AMERICAN PUBLIC HEALTH ASSOCIATION. Standard Methods for Examination of Water and Wastewater. Washington: D.C. 19.ed., 1998.

ARAÚJO, A. O.; MENDONÇA, L. A. R.; LIMA, M. G. de S.; FEITOSA, J. V.; SILVA, F. J., NESS, R. L. L; FRISCHKORN, H.; SIMPLÍCIO, A. A. F.; KERNTOPF, M. R. Modificações nas propriedades dos solos de uma área de manejo florestal na Chapada do Araripe. Revista Brasileira Ciência do Solo. v. 37, n.1, p. 754-762, 2013.

BRASIL. Portaria No 2914 de 12 de dezembro de 2011 do Ministério da Saúde. Dispõe sobre os procedimentos de controle e vigilância da qualidade da água para consumo humano e seu padrão de potabilidade. Brasília: 2011. 34 p.

CABRAL, N. R. A. J. Proposta de Solução Integrada para os Resíduos Sólidos dos Municípios de Juazeiro do Norte, Crato e Barbalha- Ceará. Dissertação (Mestrado em Saneamento Ambiental). Universidade Federal do Ceará. 1997, 157p.

CAGECE. COMPANHIA DE ÁGUA E ESGOTO DO ESTADO DO CEARÁ. Dados de Populações-Economias de Esgoto- 2003. Juazeiro do Norte, p. 2-3. 2003.

CPRM. COMPANHIA DE PESQUISA DE RECURSOS MINERAIS. Atlas dos recursos hídricos subterrâneos do Ceará - Programa de recenseamento de fontes de abastecimento por águas subterrâneas do Ceará - Diagnóstico Municipal de Juazeiro do Norte. Fortaleza, p. 8-12, 2000.

FERNANDES, F. B. P.; ANDRADE, E. M. de.; FONTENELE, S. de B.; MEIRELES, A. C. M.; RIBEIRO, J. A. Análise de agrupamento como suporte à gestão qualitativa da água subterrânea no semiárido cearense. Revista Agro@mbiente On-line, v. 4, n. 2, p. 86-95, 2010.

FRANCA, R. M. Diagnóstico sanitário das águas do riacho dos macacos e de uma bateria de poços nas suas imediações - Município de Juazeiro do 
Norte - Ceará. Dissertação (Mestrado em Saneamento Ambiental). Universidade Federal do Ceará. 2004. 170p.

FRANCA, R. M. da; FRISCHKORN, H.; SANTOS, M. R. P.; MENDONÇA, L. A. R.; BESERRA, M. da C. Contaminação de poços tubulares em Juazeiro do Norte-CE. Engenharia sanitária ambiental. v. 11, n.1, p. 92-102, 2006.

FUNCEME. FUNDAÇÃO CEARENSE DE METEOROLOGIA E RECURSOS HÍDRICOS. Boletim de Pluviometria Anual da Fundação Cearense de Meteorologia e Recursos Hídricos - FUNCEME, Juazeiro do Norte, Posto $n^{\circ} 78$, 2004.

GOMES, M.C.R.; CAVALCANTE, I. N. Aplicação da análise estatística multivariada no estudo da qualidade da água subterrânea. Revista brasileira de águas subterrâneas. v. 31. n.1, p. 134-149, 2017.

HAIR JR., J. F.; ANDERSON, R. E.; TATHAN, R. L.; BLACK, W. C. Multivariate data analysis. New Jersey. Prentice Hall, 928 p., 1998.

IBGE - Instituto Brasileiro de Geografia e Estatística. Censo geográfico 2010. Disponível em: http://www.ibge.gov.br/home/. Acessado em: $20 \mathrm{abr} / 2017$

LUCENA, L. R. F. de; ROSA FILHO, E. F. da; BITTENCOURT, A. V. L.; MONTAÑO, J. X. A migração de constituintes iônicos no aquífero Barreiras na região sul de Natal-RN, decorrente do quadro estrutural local - uma hipótese de trabalho. Revista Latino-Americana de Hidrogeologia, v. 4, n.4, p. 9-16, 2004.
MANLY, B. F. J. Multivariate statistical methods. London: Chapman e Hall, 215 p., 1998.

MENDONÇA, L. A. R. Modelagem matemática, química e isotópica de uma bateria de poços na cidade de Juazeiro do Norte- Ceará. Dissertação (Mestrado em Recursos Hídricos). Universidade Federal do Ceará. 1996. $122 p$.

SALGADO, E.V.; ANDRADE, E. M. de, FONTENELE, S. de B., MEIRELES, A C. M. Similaridade das variáveis hidroquímicas com o uso da análise multivariada, na Bacia do Salgado, Ceará. Revista Caatinga, v. 24, n. 3, p. 158-166, 2011.

SANTOS, A. C. Noções de Hidroquímica. In: FEITOSA, F. A. C.; MANOEL FILHO, J.; FEITOSA, E. C.; DEMETRIO, J. G. A. Hidrogeologia: Conceitos e Aplicações. Rio de Janeiro: CPRM e LABHID, 3. ed., revisada e ampliada, p. 325-357. 2008.

VEGA, M.; PARDO, R.; BARRADO, E.; DEBÁN, L. Assessement of seasonal and polluting effects on the quality of river water by exploratory data analysis. Water Research, v. 32, n.12, p. 3581-3592, 1998.

VICINI, L. Análise multivariada da teoria à prática. Santa Maria, 215p, 2005. 